\title{
Sports Activity and Smoking, Alcohol and Drug Abuse among Students
}

\author{
Somayeh Ahmadabadi
}

Sport Science Department, Farhangian University, Tehran, Iran.

\begin{abstract}
Background. Despite the research being accomplished so far, there is no clear answer to the question that "Does sports help to prevent and reducing the abuse of drug, alcohol, and smoking in young people as it believed in public". Objective(s). The purpose of this study was to investigate the relationship between sports activity and experience of smoking, alcohol and drug abuse among a sample of male and female students in Tehran. Methods. In a crosssectional and correlation study, 1173 male and female students from two universities; University of Tehran and Tehran University of Medical Sciences were selected to complete researcher-made questionnaires on smoking, drug and alcohol abuse, and also complete demographic questionnaires. They also responded to a sports activity questionnaire, including questions about the type and level of teamwork and activity. Results. The findings showed that males are relatively regular in sports activities than females and they are also members of sports teams. Smoking, alcohol and drug abuse were significantly higher in males than in females. Binary logistic regression analysis showed that there is no significant relationship between being athlete in males, whether they are members of the team or not, and the smoking, alcohol and drug abuse, but unorganized female athletes, outside the framework of sports teams, had reported more alcohol and drug abuse than inactive people during a year ago. Conclusion. In order to improve the accuracy and effectiveness of programs for the prevention of drug abuse through sport, paying attention to gender differences, age differences and type of sports activity (organized in the form of teams or nonorganized and individually) is critical. The findings of this study suggest that membership in sports teams of a college, especially for females should be expanded, and preventive programs should be designed through sport in a professional way -in terms of timing and content- for males and females.
\end{abstract}

KEY WORDS: Sport, Gender, Drug, Alcohol, Smoking.

\section{INTRODUCTION}

According to Iran's statistical Information Center, the majority of Iran's population is made up of youth and adolescents in 2011. Hence, in a young society, a large amount of society's problems and issues are related to this age group (1). Drug and alcohol abuse has always been one of the social impacts with adverse consequences at various levels of individual, social and economic life. Psychological and financial damages caused by smoking, drug and alcohol abuse include economic costs, death, suicide, delinquency and failed marriages (2). The exact prevalence of this problem among students and young people is not clear, but different studies

*. Corresponding Author:

Somayeh Ahmadabadi

E-mail: somayeh.ahmadabadi@gmail.com 
have expressed a different rate of 20 to $4 \%$ for the prevalence of drug abuse among students in the country (3).

So far, various ways have been proposed to prevent drug and alcohol abuse and smoking among young people. Among these, sports activities have been emphasized by researchers and policy makers as an effective strategy (4-7).

Various studies have been conducted on the effects of sport on smoking, alcohol and drug abuse, but these studies have not reported consistent results (8). A number of studies have pointed to the preventive role of sport against smoking, drug and alcohol abuse (9-13). They have suggested that sport contributes to prevention through mechanisms such as reducing stress and anxiety, increasing selfesteem, decision-making power, resistance to other people's insistence, improving the image of the individual and knowing more about the destructive effects of drugs. In contrast to this group, some other groups introduced a number of other sports activities as a risk factor for smoking, drugs and alcohol abuse, and found that competitive culture and pressure to succeed could provide basis for such high-risk behaviors $(8,14-19)$. Despite previous studies in the field of sport, this question still remains that whether there is a difference between sports activity in terms of teamwork and outside sports activities or not. According to the theory of social capital, membership in the sports team is a kind of social participation that can help promote health behaviors in various ways. These methods include increasing awareness and information, filling leisure time and reducing opportunities for engaging in high-risk activities and also cause continuous social control $(20,21)$. However, social participation does not always have a completely positive effect on the participants; sometimes, group norms and values (delinquent groups) may be at the opposite of individual and social health, in which conformity to such norms and values put participants' health in danger. In this regard, a group of studies have investigated the negative role of membership in sports team on the individuals' behavioral health $(8,22,23)$.

Evaluating the history of sport participation among 21 male and female participants aged 2861 who were under treatment and rehabilitation from drug abuse, has showed that the participation of older people -not peers- as teammates and also gaining popularity among teammates had been effective in encouraging people to drug and Alcohol abuse (8). In Iran, the study of Zadeh Mohammadi et al. (2010) showed that membership in the sports team and the participation in sports camps has relationship with an increase in alcoholism among adolescents (23). In their explanation of the higher levels of risk tendency among members of the sports team, they pointed to the stress caused by the conflict between the role of students and athletes, the conditions of sports camps, and the normative pressure of peers. The study evaluates high school adolescents and "tendency to abuse" rather than "abusive behavior". Hence, the relationship between the membership in the sport teams and the high-risk behavior among the public, especially young people in Iran needs attention. The difference between males and females in the relationship between sport participation and drug abuse is another point that has been underestimated. According to traditional socialization (24) and social control (25), females are less likely than men to engage in behaviors such as sport participation and drug abuse, which generally considers them "manly" (26, 27). Research on gender differences in the relationship between sport and smoking, alcohol and drug abuse is small and inconsistent; for instance, while Stafforter, Storger and Larsen (2005) found that membership in organized sport teams, increase the risk of alcohol abuse in male and female adolescents (28), more recent research, introduce competitive sport as a risk factor for alcohol abuse among females and a factor in preventing smoking among males (29). Despite the research being accomplished so far, there is no clear answer to the question that "Does sport help preventing and reducing the abuse of drug, alcohol and smoking in young people as it believed in public ". The discrepancy between the results of the relationship between sport and abusive behaviors makes further studies necessary. Some of this discrepancy may be related to the effect of different sports activities in or out of the framework of the team structure. Understanding these differences and current differences between males and females in this regard can help to improve the accuracy and 
effectiveness of prevention programs among young people. If risk factors were different for members and non-members males and female's athletes, some more deliberated proactive approaches should be considered. According to aforementioned, this study evaluates the role of gender in this regard in addition to evaluating the relationship between sport (individual sport against membership in the sports team) and smoking, drug and alcohol abuse. This study seeks to answer two general questions: 1) is there a relation between sport (individual sport against membership in sports team) and smoking, drug and alcohol abuse? And 2) is this relationship different for male and female students?

\section{MATERIALS AND METHODS}

Method. This study is correlational and cross-sectional.

Participants. The statistical population of this study is male and female students studying in two universities in 2015: University of Tehran and Tehran University of Medical Sciences. 1173 students including 639 students from University of Tehran and 534 from Tehran University of Medical Sciences were analyzed. $57.3 \%$ (669 participants) of them were female. The average age of students was 21.78 years $(\mathrm{SD}=2.8)$. The demographic characteristics of the respondents have been presented in Table 1.

Table 1. Demographic characteristics of students participating in research

\begin{tabular}{ccc}
\hline & frequency & \% \\
\hline gender & & \\
female & 669 & 57.3 \\
male & 498 & 42.7 \\
age & & \\
$18-20$ years & 432 & 37.4 \\
$21-25$ years & 635 & 55.0 \\
26 years and older & 87 & 7.5 \\
university & & \\
Tehran & 534 & 45.5 \\
Tehran University of medical science & 639 & 54.5 \\
Academic level & & \\
Assistant & 27 & 2.3 \\
Bachelor & 819 & 70.7 \\
Doctoral & 313 & 27.0 \\
Educational level & & \\
first & 143 & 34.6 \\
second & 131 & 31.7 \\
third & 73 & 17.7 \\
Fourth or higher & 66 & 16.0 \\
Marital statues & & \\
single & 1086 & 93.7 \\
married & 70 & 6.0 \\
divorced & 3 & 0.3 \\
Employment statues & 970 & 84.8 \\
unemployed & 174 & 15.2 \\
\hline employed & &
\end{tabular}

Data collection method. Sampling in this research was multi-staged, being accomplished in accessible and affordable way. So that, in addition to saving time and costs, sampling deficiencies reaches to minimum amount. Since the various disciplines of science within the universities have made its construction incongruous, this heterogeneous population was initially categorized in the form of homogeneous groups (technical-engineering, humanities, medicine, paramedics). After this step, the questioner went to the colleges and 
distributed questionnaires among the respondents.

Research Tools. We used from following tools:

Sports activity. The respondents were asked following question in order to measure sports activity "Do you regularly sport / have physical activity?" The answer classes included two options: yes $(=1)$ and no $(=0)$. In the case of a positive answer, they were asked "Do you regularly spend a few sessions a week on this sport?" Options included once, twice, three times, and more. Membership in the sport teams with the question of "Are you a member of a sport team?" and two options were answered yes $(=1)$ and No $(=0)$. The level of team membership was evaluated in the question "at what level did /do you play? “

The response included schools, colleges and universities in levels of city, state and nation. This variable was analyzed with two levels of non-professional (schools / college / university) and professional (city / state / nation). Finally, to provide a clearer picture of the above items, respondents were divided into three groups: (1) inactive people (with no sports activities and team memberships); (2) active people without team membership; and (3) active members with team memberships.

Drug Abuse. Smoking has been evaluated in two periods of lifetime and a month ago with two questions: "Have you ever smoked" and "Have you smoked in the past 30 days?" To measure alcohol abuse in two time periods of up to now and a year ago, two questions were asked. These questions are: "some young people drink alcohol, have you ever drink any?" and "have you drink any alcohol in the past 12 months?".

Following questions were asked respondents in order to measure drug abuse: "Have you ever used one of the following drugs (opium, heroin, hashish, glass, ecstasy)" and "Have you used these drugs during a year ago?" The responses included two options, yes and no. Each of these nominal variables is represented by an arbitrary cryptographic method, yes $=1$ and no $=0$ as an interval variable in analysis (30). In addition, the demographic information questionnaire including age (year of birth), marital status (single or married, divorced), employment status (unemployed or employed), educational level (associate, bachelor, doctoral), and field of study (Engineering, Humanities, Medical, Paramedical, Arts and Basic Sciences) were completed by respondents. These variables in the present study were evaluated in terms of intervention in the relationship between sport and drug abuse, and those who had a significant relationship with both the independent and the dependent variable were controlled in the final analysis.

Statistical Analysis. Data were analyzed using SPSS-18 software, using descriptive statistics and analytical statistics including Chisquare and binary logistic regression analysis. The binary logistic regression variable is used to predict dichotomous variables (here, smokers/non-smokers and users/non-users drugs or alcohol). The probability rate of a state, the odds ratios and confidence intervals has been reported $95 \%$ in this analysis (31). In the independent variable, inactive people are considered as reference groups, and the other two groups are active / without team membership and active / with team membership are compared with this group. The significance level of the tests in this study was considered 0.05 .

\section{RESULTS}

Chi-square results (Table 2) showed that in addition to gender, a variable that was related to both sport membership and drug abuse was university and employment status; employed in comparison with unemployed people have reported higher rates of sports activities (44.8\% vs. $35.7 \%(\mathrm{P}=0.02)$, smoking during a month ago $(21.3 \%$ vs. $12.6 \%, p=0.002)$, drug abuse in the past year $(6.3 \%$ vs. $2.6 \% \mathrm{P}=0.009)$, and alcohol abuse in the past year $(26.4 \%$ vs. $12.7 \%$, $\mathrm{p}=0.001)$. University of Tehran students have smoked more than Tehran University of medical students during a month ago (19.6\% vs. $7.1 \%, \mathrm{p}$ $=0.001)$, have used alcohol during a year ago $(18.9 \%$ vs. $9.6 \%, \mathrm{p}=0.001)$ and drug during a year ago ( $4.5 \%$ vs. $1.3 \%, \mathrm{p}=0.001)$. However, a higher percentage of males in Tehran University of Medical Sciences had a positive attitude toward sports activities than male students in University of Tehran (51.5\% vs. $40.4 \%, \mathrm{p}=$ 0.02). 
Among 1173 respondents, 431 participants $(36.7 \%)$ of them sport regularly. Nearly two thirds of students are inactive. $16 \%$ of athlete students are members of the sport team. Males have relatively more regular activity in sports activities and in sport teams ( $p<0.0001)$ and are members of sport teams than females, but there is no significant difference in their team level ( $p$
$=0.71)$. One-third of students have already smoked, more than one in five have already had alcohol abuse, and $7 \%$ of them have ever experienced using even one kind of drugs. Comparison of male and female students showed that smoking, alcohol and drug abuse in males were significantly higher than females ( $p$ $<0.0001)$.

Table 2. Smoking, alcohol and drug abuse and various dimensions of sport among male and female students

\begin{tabular}{|c|c|c|c|c|c|c|c|}
\hline & \multicolumn{2}{|c|}{ Total $(n=1173)$} & \multicolumn{2}{|c|}{ Females $(n=669)$} & \multicolumn{2}{|c|}{$\operatorname{Males}(n=498)$} & \multirow{2}{*}{$\begin{array}{l}\text { Chi-square } \\
\text { (p) }\end{array}$} \\
\hline & frequency & $\%$ & frequency & $\%$ & frequency & $\%$ & \\
\hline \multicolumn{8}{|l|}{ Drug abuse } \\
\hline Smoking up to now (yes) & 306 & 30.6 & 102 & 18.2 & 203 & 46.7 & $92.90(0.00)$ \\
\hline Smoking in the a month ago(yes) & 163 & 13.9 & 40 & 6.0 & 123 & 24.7 & $83.25(0.00)$ \\
\hline Alcohol abuse up to now (yes) & 241 & 22.8 & 77 & 12.9 & 163 & 35.9 & $77.45(0.00)$ \\
\hline $\begin{array}{l}\text { Alcohol abuse in the past } 12 \\
\text { months(yes) }\end{array}$ & 172 & 14.7 & 53 & 7.9 & 118 & 23.7 & $56.79(0.00)$ \\
\hline Drug abuse up to now (yes) & 65 & 6.68 & 14 & 2.6 & 51 & 12.3 & $34.72(0.00)$ \\
\hline $\begin{array}{l}\text { Drug abuse in past } 12 \text { months } \\
\text { (yes) }\end{array}$ & 36 & 3.1 & 8 & 1.2 & 28 & 5.6 & $18.71(0.00)$ \\
\hline \multicolumn{8}{|l|}{ Sport } \\
\hline Sport activity (yes) & 431 & 36.7 & 182 & 27.2 & 195 & 39.2 & $18.64(0.00)$ \\
\hline $\begin{array}{l}\text { Number of active sessions per } \\
\text { athletes) }\end{array}$ & r week (a & nong & & & & & $7.46(0.02)$ \\
\hline once & 83 & 22.0 & 51 & 28.0 & 32 & 16.4 & \\
\hline twice & 103 & 27.3 & 47 & 25.8 & 56 & 27.8 & \\
\hline Third times or more & 191 & 50.7 & 84 & 46.2 & 107 & 54.9 & \\
\hline Joining to a sport team(yes) & 188 & 16.0 & 41 & 8.5 & 67 & 18.2 & $17.50(0.00)$ \\
\hline \multicolumn{8}{|c|}{$\begin{array}{l}\text { Team level (among team members: } 188 \\
\text { person) }\end{array}$} \\
\hline School/ college/ university & 118 & 67.0 & 20 & 55.6 & 31 & 51.7 & $0.14(0.71)$ \\
\hline City/state/country & 58 & 33.0 & 16 & 44.4 & 29 & 48.3 & \\
\hline $\begin{array}{l}\text { Activity- membership } \\
\text { inactive }\end{array}$ & 734 & 63.0 & 460 & 68.8 & 274 & 55.2 & $30.65(0.00)$ \\
\hline $\begin{array}{l}\text { Active- } \\
\text { membership }\end{array}$ & 244 & 20.9 & 133 & 19.9 & 111 & 22.4 & \\
\hline Active- team member & 187 & 16.1 & 76 & 11.4 & 111 & 0.42 & \\
\hline
\end{tabular}

Table 3 shows that there is no significant difference between being athlete or notwhether being a member of a team or not- and smoking (in a month ago), drug and alcohol abuse (in a year ago) among males. In contrast, the female athletes working outside the framework of sport teams have significantly used alcohol and drugs than inactive people. These results are independent from demographic variables.

\section{DISCUSSION}

In this study, although male students have reported more alcohol and drug abuse and sports activities than females, the relationship between sport and drug abuse among them was not significant. Among females, however, the separation of sports activities into membership and non-membership in the sport teams showed that unorganized sports activities increase the risk of abuse. 
Table 3. Results of dual and multiple logistic regressions between sport activity and smoking, alcohol and drugs (odds ratios (confidence intervals 95\%) among female students and males

\begin{tabular}{|c|c|c|c|c|c|c|c|c|c|}
\hline & \multicolumn{3}{|c|}{$\begin{array}{c}\text { Smoking (during a month ago } \\
=\text { yes })\end{array}$} & \multicolumn{3}{|c|}{$\begin{array}{l}\text { Alcohol abuse (during a year } \\
\text { ago=yes) }\end{array}$} & - & \multicolumn{2}{|c|}{$\begin{array}{l}\text { Drug abuse (during a year } \\
\text { ago=yes) }\end{array}$} \\
\hline & $\%$ & Model 1 & Model 2 & $\%$ & Model 1 & Model 2 & $\%$ & Model 1 & Model 2 \\
\hline \multicolumn{10}{|l|}{$\underline{\text { males }}$} \\
\hline Inactive (reference group) $(n=274)$ & 23 & 1 & 1 & 21.9 & 1 & 1 & 5.5 & 1 & 1 \\
\hline Active/ non-members in groups $(n=111)$ & 27.9 & $\begin{array}{c}1.71 \\
(0.3-81.61)\end{array}$ & $\begin{array}{c}1.25 \\
(0.74-2.10)\end{array}$ & 28.8 & $\begin{array}{c}1.45 \\
(0.87-2.38)\end{array}$ & $\begin{array}{c}1.43 \\
(0.85-2.39)\end{array}$ & 4.5 & $\begin{array}{c}0.81 \\
(0.29-2.29)\end{array}$ & $\begin{array}{c}0.82 \\
(0.30-2.33)\end{array}$ \\
\hline Active/ members in groups $(n=111)$ & 26.1 & $\begin{array}{c}1.63 \\
(0.64-4.14)\end{array}$ & $\begin{array}{c}1.40 \\
0.82-2.38)\end{array}$ & 23.4 & $\begin{array}{c}1.1 \\
(0.64-1.84)\end{array}$ & $\begin{array}{c}1.2 \\
(0.68-2.04)\end{array}$ & 7.2 & $\begin{array}{c}1.34 \\
(0.55-3.26)\end{array}$ & $\begin{array}{c}1.54 \\
(0.62-3.83)\end{array}$ \\
\hline \multicolumn{10}{|l|}{$\underline{\text { females }}$} \\
\hline inactive (reference group) $(n=460)$ & 5 & 1 & 1 & 6.5 & 1 & 1 & 0.7 & 1 & 1 \\
\hline Active/ non-members in groups $(n=133)$ & 8.3 & $\begin{array}{c}1.30 \\
(0.78-2.14)\end{array}$ & $\begin{array}{c}1.73 \\
(0.81-3.71)\end{array}$ & 12.8 & $\begin{array}{c}2.10 \\
(1.12-3.94)\end{array}$ & $\begin{array}{c}2.07 \\
(1.09-3.95)\end{array}$ & 3.8 & $\begin{array}{c}5.95 \\
(1.40-25.23)\end{array}$ & $\begin{array}{c}6.6 \\
(1.46-29.7)\end{array}$ \\
\hline Active/ members in groups $(n=76)$ & 7.9 & $\begin{array}{c}1.18 \\
(0.71-1.97)\end{array}$ & $\begin{array}{c}1.62 \\
(0.63-4.19)\end{array}$ & 7.9 & $\begin{array}{c}1.23 \\
(0.49-3.06)\end{array}$ & $\begin{array}{c}1.20 \\
(0.48-3.02)\end{array}$ & 0.7 & $\mathrm{c}$ & $\mathrm{c}$ \\
\hline
\end{tabular}


In this research, sport (whether individually or in a team) did not have a protective and precautionary role against the abuse of male students. This finding was in line with the results of some other studies that identified sport as a risk factor for drug abuse (smoking, alcohol) (8, 32,33 ), but it is not accordant with research findings that found sport to be a preventive factor in smoking and drug abuse $(9-13,19,34)$.

To explain this non-relationship, there are a few possible explanations: First, the peak time of a sports activity and team membership is the adolescence that decreases with the transition to adulthood and conflicts in life. Most of the highrisk behaviors also begin and continue from adolescence. It is likely that abusive behaviors among high risk males have already begun and stabilized and are not affected by sport in youth. In a systematic study on accomplished studies in this scope, it became clear that sport membership increase the risk of illegal drug abuse only during the scholastic period (35). This explanation highlights the importance of adolescence and scholastic period in the formulation of sport prevention programs, especially among males, since precautionary efforts in this area become less effective as males students grow older and pass the adolescence.

Second, the discrepancy in the findings of this research with some previous results can be related to the methodological differences (such as the statistical society and the measurement) between this research and other research; the results obtained in this study are based on the study of young students and not professional athletes (13) or adolescents $(9,12)$. Differences between these groups, such as differences in sport history, attitudes to sport activities and its importance in their life, may have contributed to the impact of sport activities on drug and alcohol abuse and smoking.

Third, it is possible that the relationship between sport and drug abuse in males has related to other variables not investigated in this study; for example, it has been shown that abuse in athletes is influenced by their type of sports activity $(33,36-38)$; As the rate of tendency to smoking, alcohol and drugs in professional athletes and athletes of high schools is higher than other athletes. This finds the importance of conducting further research on the effects of various sports activities.

The second important finding of this study was the positive relationship between exercising out of a team on alcohol and drug abuse among females. According to the findings of this study, non-sport activities make females more vulnerable to abuse than females who never sport. This finding shows the importance of exercising in the form of a team organization, which is referred to in social capital theory as social participation. Females are less likely to suffer from social harm like abuse, before entering to the university due to social control. By entering university, not only access to alcohol and drugs for females will increase, but exposure to stress, social and educational pressures such as university exams will increase their tendency to abuse among female students $(39,40)$. Some studies have found that social changes, such as modernization, and females' efforts to break down traditional gender patterns, have led to an increase in their tendency to drug and alcohol abuse (17). In addition, in today's society, females are subjected to additional social pressures for slimming, which they carry out in a variety of ways, such as surgery, nutrition, and heavy sport. Recent research has shown that treatment of obesity, fitness, and juicy skin are among the main causes of females' tendency to drugs. Also sport halls are among advertising, promotion, prescription and distribution centers of drug abuse among them $(41,42)$. It seems that sports activities in sport halls with the aim of slimming and not being healthful increase the probability of alignment with high-risk norms (such as drug abuse for slimming). Hence, based on the theory of social capital, this form of sport participation considers as a negative social capital.

\section{CONCLUSION}

In general, this study showed that there is no significant relationship between being an athlete or not among males - whether they are members of the team or not - and smoking and the abuse of alcohol and drugs, but unorganized female athletes exercising outside the framework of sport teams, have reported more drug and 
alcohol abuse during a year ago. The first finding of this study showed that sport activity, as publicly believed, does not always help to reduce social harm. In a student's life, sports not in the form of a team or non-organized - are not related to smoking, alcohol and drug abuse in males. This finding emphasizes the need for early prevention of abuse among males. Sport as a preventive strategy should be considered before passing into youth and stabilization of high-risk behaviors in males. The second finding of the study showed that among female students, exercising outside the team is a risk factor for drug and alcohol abuse. The Ministry of Health considers sport-related injuries due to inadequate monitoring on them and the weakness of laws and regulations in dealing with risk factors. This reference proposes increasing awareness and life skills, strengthening alternative activities to drug abuse, counseling and intervention, and strengthening religious and moral beliefs in target groups to prevent this social harm. In general, the results of this study suggest that in the case of using sport in reducing abuse, attention to factors such as the type of sports activity, age and gender differences can improve the accuracy and effectiveness of preventive efforts.

Research Constraints. The results of this research should be considered due to its methodological constraints. The first constrain of this study was the sample of study which was constrained to males and females employed in public universities. Due to the importance of this issue, further studies are recommended by selecting more varied samples of adolescents and youth. The second constraint was the inadequate sample size among females, which led to a reduction in the accuracy of the estimation and a wider range of confidence. Also, despite the control of a number of demographic variables in this study, this research failed to control the effects of variables such as values and cultural norms, familial and psychological characteristics of the relationship between sport and smoking, alcohol and drug abuse. More comprehensive research is suggested by controlling the effect of intervener variables in this regard. In addition, this research has not addressed directly the issue of sporting halls, but more research seems to be needed to investigate their features and potentials in discussing the abuse of some harmful drugs. The next constraint of this research was a cross-sectional study of relationships between variables. Longitudinal studies with a larger sample size, and considering more dimensions of sport, can provide more reliable findings.

\section{APPLICABLE REMARKS}

- Preventive programs should be designed for drug abuse both separated and specialized - in terms of time and content- for males and females, and consider their psychological and social differences.

- Expanded student sport teams and students - especially females - should have been encouraged to participate more in them.

- The risk factors that affect both sports activities and drug abuse, such as the feeling of physical disproportion and desire for slimming and fitness, should be considered and their related interventions should be designed.

- Effective monitoring should increase on sport halls out of university - As one of the possible areas for recommending and encouraging female athletes to use various types of harmful drugs.

\section{REFERENCES}

1. Gans J, Blyth D, Elster A, Gaveras L. Profiles of Adolescent Health Volume I: America's Adolescents: How Healthy Are They? Chicago, Ill: American Medical Association. 1990.

2. Raeisei A, Arbabisarjou A, Mojahed A. An Investigation of the Socio-Economic Status of the Addicts in Lashar and Nikshahr County and Its Comparison With Ordinary People. Global journal of health science. 2015;7(3):194. 
3. Siam S. Drug abuse prevalence between male students of different universities in rasht in 2005. Zahedan Journal of Research in Medical Sciences. 2006;8(4):9-15 [Article in Farsi].

4. Dunn MS, Wang MQ. Effects of physical activity on substance use among college students. American Journal of Health Studies. 2003;18(2/3):126.

5. Pate RR, Heath GW, Dowda M, Trost SG. Associations between physical activity and other health behaviors in a representative sample of US adolescents. American journal of public health. 1996;86(11):1577-81.

6. Pate RR, Pratt M, Blair SN, Haskell WL, Macera CA, Bouchard C, et al. Physical activity and public health: a recommendation from the Centers for Disease Control and Prevention and the American College of Sports Medicine. Jama. 1995;273(5):402-7.

7. Lambert M. Provider Screening for Adolescent Alcohol and Other Drug Use at Jefferson Health: Why It's Important and How We Can Improve. Population Health Matters (Formerly Health Policy Newsletter). 2017;30(3):4.

8. de Grace LA, Knight CJ, Rodgers WM, Clark AM. Exploring the role of sport in the development of substance addiction. Psychology of Sport and Exercise. 2017;28:46-57.

9. Aaron DJ, Dearwater SR, Anderson R, Olsen T, Kriska AM, Laporte RE. Physical activity and the initiation of high-risk health behaviors in adolescents. Medicine \& Science in Sports \& Exercise. 1995.

10. Thorlindsson T, Bernburg J, editors. Sport, peers and substance use. The annual meeting of the American Sociological Association, Philadelphia; 2005.

11. Donato F, Assanelli D, Marconi M, Corsini C, Rosa G, Monarca S. Alcohol consumption among high school students and young athletes in north Italy. Revue d'epidemiologie et de sante publique. 1994;42(3):198-206.

12. Winnail SD, Valois RF, McKeown RE, Saunders RP, Pate RR. Relationship between physical activity level and cigarette, smokeless tobacco, and marijuana use among public high school adolescents. Journal of School Health. 1995;65(10):438-42.

13. Szabo A, Griffiths M, Aarhus Høglid R, Demetrovics Z. Drug, nicotine, and alcohol use among exercisers: does substance addiction co-occur with exercise addiction? Addictive Behaviors Reports. 2018;7:26-31.

14. Melnick MJ, Miller KE, Sabo DF, Farrell MP, Barnes GM. Tobacco use among high school athletes and nonathletes: Results of the 1997 Youth Risk Behavior Survey. Adolescence. 2001;36(144):727.

15. Peretti-Watel P, Guagliardo V, Verger P, Pruvost J, Mignon P, Obadia Y. Sporting activity and drug use: Alcohol, cigarette and cannabis use among elite student athletes. Addiction. 2003;98(9):1249-56.

16. Rainey CJ, McKeown RE, Sargent RG, Valois RF. Patterns of tobacco and alcohol use among sedentary, exercising, nonathletic, and athletic youth. Journal of School Health. 1996;66(1):27-32.

17. Moore MJ, Chudley E. Sport and physical activity participation and substance use among adolescents. Journal of Adolescent Health. 2005;36(6):486-93.

18. Watten R. Sports, physical exercise and use of alcohol. Scandinavian journal of medicine \& science in sports. 1995;5(6):364-8.

19. Wechsler H, Davenport AE, Dowdall GW, Grossman SJ, Zanakos SI. Binge drinking, tobacco, and illicit drug use and involvement in college athletics: A survey of students at 140 American colleges. Journal of American College Health. 1997;45(5):195-200.

20. Lindström M, Hanson BS, Östergren P-O. Socioeconomic differences in leisure-time physical activity: the role of social participation and social capital in shaping health related behaviour. Social science \& medicine. 2001;52(3):441-51.

21. Bolin K, Lindgren B, Lindström M, Nystedt P. Investments in social capital-implications of social interactions for the production of health. Social science \& medicine. 2003;56(12):2379-90.

22. Rodriguez D, Audrain-McGovern J. Team sport participation and smoking: Analysis with general growth mixture modeling. Journal of Pediatric Psychology. 2004;29(4):299-308.

23.zadehmohammadi A, ahmadabadi, Z., ahmadabadi, S., rafeieborojeni, M. Sport and Risk- Taking against Substance Abuse in students of Tehran High Schools. Journal of Motor Learning and Movement. 2010;2(1):5-24.

24. Messner MA, Sabo DF. Introduction: Toward a critical feminist reappraisal of sport, men, and the gender order. Sport, men, and the gender order: Critical feminist perspectives. 1990:1-15.

25. Hirschi T, Stark R. Hellfire and delinquency. Social Problems. 1969;17(2):202-13.

26. Narenjiha H RH, Baghestani AR, Nouri R, Ghafouri B, Soleimaninia L, et al. Rapid Situtional Assessment of Substance Abuse in Iran. Final Report of Research. Tehran (in Persian): Darious Institute; 2006.

27. Telford RM, Telford RD, Olive LS, Cochrane T, Davey R. Why Are girls less physically active than boys? findings from the LOOK longitudinal study. PloS one. 2016;11(3):e0150041.

28. Stafström M, Ostergren P-O, Larsson S. Risk factors for frequent high alcohol consumption among Swedish secondary-school students. Journal of studies on alcohol. 2005;66(6):776-83. 
29. Tahiraj E, Cubela M, Ostojic L, Rodek J, Zenic N, Sekulic D, et al. Prevalence and factors associated with substance use and misuse among Kosovar adolescents; cross sectional study of scholastic, familial-, and sportsrelated factors of influence. International journal of environmental research and public health. 2016;13(5):502.

30. Foster J. A Guide for Statistics in the Behavioral Sciences. New York, NY: Momentum Press; 2016. 112 p.

31. Harrell Jr FE. Binary logistic regression. Regression modeling strategies: Springer; 2015. p. 219-74.

32. Davis TC, Arnold C, Nandy I, Bocchini JA, Gottlieb A, George RB, et al. Tobacco use among male high school athletes. Journal of Adolescent Health. 1997;21(2):97-101.

33. Denault A-S, Poulin F. A detailed examination of the longitudinal associations between individual and team sports and alcohol use. Addictive behaviors. 2018;78:15-21.

34. Lynch WJ, Robinson AM, Abel J, Smith MA. Exercise as a Prevention for Substance Use Disorder: a Review of Sex Differences and Neurobiological Mechanisms. Current Addiction Reports. 2017;4(4):455-66.

35. Kwan M, Bobko S, Faulkner G, Donnelly P, Cairney J. Sport participation and alcohol and illicit drug use in adolescents and young adults: A systematic review of longitudinal studies. Addictive behaviors. 2014;39(3):497506.

36. Ford JA. Substance use among college athletes: A comparison based on sport/team affiliation. Journal of American College Health. 2007;55(6):367-73.

37. Martin M. The use of alcohol among NCAA Division I female college basketball, softball, and volleyball athletes. Journal of Athletic Training. 1998;33(2):163.

38. Sami S, Mahmoudi S, Karimiani N. Desire of Athlete and Non-athlete Students to Drugs Use. Annals of Applied Sport Science. 2014;2(4):49-54.

39. Garousi S, Mohammadi Dolatabad K. Delineation of the Lived Experiences of Drug Dependent Women. Sociology of Women (Journal of Woman and Society). 2011;2(1):55-74 [Article in Farsi].

40. Rahimi MA. A review on the prevalence and the patterns of drug abuse in women in Iran. Social Welfare. 2004;3(12):203-26 [Article in Farsi].

41. Noori R, Rafiey H, Azizabadi-Farahani M, Khoddami-Vishteh H-R, Mirabi P, Farhadi M-H, et al. Risk factors of suicidal ideation and attempt in women with drug user spouses. Journal of the Chinese Medical Association. 2013;76(11):648-52.

42. Noori R, Daneshmand R, Farhoudian A, Ghaderi S, Aryanfard S, Moradi A. Amphetamine-Type Stimulants in a Group of Adults in Tehran, Iran: A Rapid Situation Assessment in Twenty-Two Districts. Iranian Journal of Psychiatry and Behavioral Sciences. 2016;10(4). 